\title{
Social Support and the Welfare of Older Adults in Conflict Situations in Nigeria \\ DOI: $10.36108 / \mathrm{NJSA} / 4102 / 12(0161)$
}

\author{
Theresa Uchechi Ejikeme ${ }^{1}$ \\ Gray Goziem Ejikeme ${ }^{2}$ \\ Fatai Adesina Badru ${ }^{3}$ \\ Francis B.A. Akwash ${ }^{4}$
}

${ }^{1}$ Department of Educational Foundations, Faculty of Education, Faculty of Social Sciences, University of Jos, Nigeria

${ }^{2}$ Department of Sociology, Faculty of Social Sciences, University of Jos

${ }^{3}$ Department of Sociology, Faculty of Social Sciences, University of Lagos

${ }^{4}$ Department of Psychology, Nasarawa State University, Nasarawa

\begin{abstract}
This study is a desk review of the social support and welfare of older adults in conflict situations with respect to the situations in the USA and Nigeria. It indicates that there are numerous facilities for meeting the counselling and psychological needs of older persons in all situations in America contrary to the situation in Nigeria. The elderly among victims of severely traumatic and stressful events such as religious and ethnic conflicts in Nigeria have various psychosocial, economic, financial, material, and counselling needs. The stress-coping strategies of the elderly conflict victims involve drinking and alcohol abuse. There is the scarcity of professional counsellors, social gerontologists, psychologists, social workers and other human service providers that can assist them cope effectively with the stress of conflict situations. The paper concludes that the services of counsellors, social gerontologists, social workers, and psychologists are imperative for older adults to cope successfully with stressful challenges without resorting to abuse of drugs and exacerbating their age-related problems. It therefore suggests how human service providers can respond effectively to the psychosocial needs of older adults in conflict situations in the country.
\end{abstract}

Keywords: social support, psychosocial needs, traumatic life events, conflict situation, older adults

\section{Introduction}

Conflicts are becoming frequent and devastating across the globe especially in countries where many people compete for limited national resources and perceive that their religious freedom is violated. In recent years, the northern parts of Nigeria have been troubled by violent conflicts which are stressful and traumatic life events particularly, bomb blasts, reoccurring inter-religious and inter-ethnic conflicts and hostilities, leading to internal displacement of persons of various ages. Conflict situations generate severe stress which can impact differentially on people of different age cohorts. According to a research by the University of Liverpool (2013: 1), "traumatic life events are the biggest cause of anxiety and depression, but how a person thinks about these events 
determines the level of stress". This is in line with the view that how one perceives a situation largely influences how one responds or reacts to it. And so, where maladaptive thoughts and perceptions of older adults about stressful life events are not modified through professional interventions, they can develop depression, start or increase alcohol use, make suicidal attempts, especially if they have unassisted and untreated age-related problems that demand professional interventions.

These conflict situations as sources of severe stressful life events impact differentially on male and female individuals (children, adolescents, adults and older adults), families and communities and the larger society in which they exist. Older adults ordinarily experience the stress of ageing and constitute a highly vulnerable population in the reoccurring conflicts in Nigeria, and so, the psychosocial impact of these frequent and severe conflicts on their physical and mental health cannot be ignored. Research evidence on the scope of social support and professional intervention available to older adults to cope with the combination of age-related problems and the stress of conflict situations is a basic essential step towards enhancing the welfare of the afflicted.

Performing psychosocial assessment of traumatized older adults especially in conflict situations and providing services to meet the counselling and psychosocial needs of older adults are tasks that demand the expertise of professionals such as counsellors, social gerontologists, clinical social workers, and psychologists. In the USA there are several systematic, empirical studies on life events and alcohol behaviour among older adults (LaGreca et al., 1998); assessment of mental health services and older minorities (Fellin \& Powell, 1988); diagnostic validity and difficulties in assessing substance abuse in older adults (Corley et al., 2006); older adults with substance/alcohol abuse problems (Shibusawa et al., 2006), and others. But there is little or no research evidence in Nigeria on the psychosocial impact of the frequent and severe conflicts on older adults and the psychological and social support services for them. This is a major gap in knowledge this exploratory study intends to fill.

\section{Literature Review}

In this section, effort is made to establish from literature search the need for inhome supportive services and community-based care for frail older adults with chronic alcohol related illnesses and functional disabilities especially in conflict situations in Nigeria. It will also demonstrate how their psychosocial needs can precipitate to abuse of alcohol as maladaptive stress coping strategy which can exacerbate their age-related medical problems, if they are not psychosocially assessed and managed by counsellors, social workers, gerontologists and psychologists.

Older adults constitute a fast growing segment of the population. With age, the risk for developing chronic diseases such as arthritis, rheumatism, dementia, depression, Parkinson's disease, sclerosis, diabetes, stroke and glaucoma increases (Williams \& Torrens, 2008) and so, many of the older adults are managing chronic illnesses and functional disabilities that are often 
undiagnosed and untreated across the globe. Ejikeme (2014) explained that the increasing population of older adults in Nigeria presents more serious problems for providers of services than it does in America which is a developed country that has long experienced such increases in the aged population age, and has more resources for facing the challenges arising from the ageing. He observed that there is an increasing need for in-home supportive services for frail older adults with functional disabilities in especially in conflict situations in Nigeria.

Data on the number of older adults aged 65 years and above with chronic diseases and functional disabilities and in need of long-term care in Nigeria are scarce. However, older adults with chronic illness conditions and disabilities in the country are not completely without some formal and informal care; they receive medical care depending on the severity of their health issues and the affordability of nursing home or hospital care. But once their health conditions can allow them to remain at home, they prefer to remain at home to receive care from family support systems and friends. In an era of globalization, and migration some of these ageing disorders are exacerbated by lack of extended family or caregiver support services and help with activities of daily living due to the migration of the younger generations from rural communities to urban centres especially for occupational and educational reasons. With the weakening of the extended family support system and increasing diversion of care towards the nuclear family, the tendency is for middle-aged adults who fend for their biological children in cities to hire informal caregivers to provide in-home help or services to their chronically sick parents in both rural and urban areas in the country, especially when they lose the ability to live at home due to functional disabilities.

What are some of the lifestyles and facilities that enable older adults live better, happier, healthier lives? In the USA, various terms such as patients, residents, clients, and participants are used to refer to older adults who use long-term services: hospitals, nursing homes, home care, adult day services, outreach, assisted and independent living facilities, wellness programs, chronic disease self-management programs, care coordination programs (e.g., home help coordinating agency), hospices, and durable medical equipment. It is obvious from the list that there are numerous facilities in the USA for meeting the counselling and psychological needs of older persons in all situations including war and conflict situations. Of all these facilities for the care of older adults, in-home and community-based care services have prospects of meeting the health, learning, nutritional, fitness, housing, safety and security needs of older adults with health and social challenges in Nigeria.

In conflict situations in Nigeria, in-home supportive services for frail older adults with chronic health challenges and functional disabilities may be disrupted. And where this happens, it may necessitate their evacuation and placement in refugee camps where counselling, social work and psychological services for the prevention and management of anxiety, stress, depression and 
suicidal tendencies among sick elders are imperative for building their capacity to make appropriate and effective stress coping responses and become psychosocially stabilized. Coping mechanism for traumatic life events in the lives of older adults induce abuse of alcohol which exacerbate their age-related problems.

Literature on older adult substance abuse tends to draw the link between elderly alcohol behaviour and the physical changes and stress of ageing. Drinking among older adults is not as prevalent as it is among younger generations (Berkman, 2006). La Greca et al. (1988) hypothesized that stressful life events are closely linked with older adult alcohol behaviour. This presupposes that "such stressful life events lead to an increase in or initiation of alcohol consumption or drinking problems after reaching elderly years, a phenomenon referred to as late onset (Glatt et al., 1978). In other words, drinking is viewed as a reaction to or a strategy for coping with stressful life events such as seemingly sudden retirement, loss of job, loss of vision, loss of relationship, loss of social support network, loss of economic security, isolation, alienation, troublesome anxiety, depression, and other physical and sensory problems that can confront older adults across the globe.

This thinking is consistent with "the research literature in which alcohol use is related to a response stressful situations, events, and anxiety" (Stockwell et al., 1982). However, it was observed that there is a paradigm shift in gerontological research away from the impact of life events and now focuses on "the bivariate relationship of life events to a given outcome (La Greca et al., 1988). The authors highlighted the important functions of social support networks in ageing research, health and ageing as means of mitigating the impact of stress, and the tendency of older adults using maladaptive means of coping with stress of ageing such as the use of alcohol and other substances. Traumatic life events in the lives of older adults may not induce their abuse of alcohol and exacerbate their age-related problems such dementia and depression if they are provided with quality health care and social support.

While recognising the importance of social support networks, La Greca et al. (1988) admonished that the individual's coping strategies should not be ignored. This is because older adults should be encouraged by their caregivers to help themselves and be socially engaged and involved where they can rather depend solely on social support networks which may be unpredictable or unavailable. As La Greca et al. ibid explained, dependency produces an increased vulnerability to stress in a way that the more an older adult feels unable to handle a challenge (e.g. retirement), the greater the effect of stress. The report by La Greca et al. ibid suggests that caregivers or interventions designed to help older adults at risk for alcohol use as means of manageing stress should explore measures that stimulate in older adults coping skills that will make them feel self-reliant, and able to face up to the challenges of a life event or traumatic stress without the use of drugs. They feel satisfied and happy when they are able to meet the demands of a stressful environment on their own. This is why older adults need life-long education to empower them 
become re-engaged in paid work and have some economic security to purchase their medications and solve other problems without being helpless and dependent on others for support, if they can.

Shibusawa (2006) observes that alcohol, drug abuse and misuse among older adults are among the increasing mental health problems in the USA. The problems according to Shibusawa, "remain that undiagnosed and undertreated and have been referred to as an invisible epidemic (Centre for Substance Abuse Treatment [CSAT], 1998). With the ageing of baby boomers, a cohort with more liberal attitudes towards substance use than previous cohorts, the problem is expected to increase in the coming years" (Shibusawa, 2006: 141). Shibusawa also notes that "although alcohol abuse by older adults is less prevalent than in younger populations, it is more difficult to detect, particularly the workplace is where alcohol and drug problems are frequently detected." (p. 143). Accurate assessment of a behavioural problem is a basic, essential step towards successful intervention. As Corley et al. (2006) noted, "the treatment of alcohol and substance use disorders in the older adult is inherently tied to the assessment procedures used to diagnose these disorders and the segment of the population found to manifest these problems" (509).

\section{Conclusion arising from literature reviewed}

Some of the studies reviewed on needs assessment and provision of care for older adults in Europe and America were not longitudinal researches. Issues such as the life events - alcohol behaviour link among older adults raised in the report by Corley et al. (2006) are better addressed by conducting a longitudinal research. And so, research continues in this field. Rather than use alcohol and other drugs as means of escape from stress, older adults can be self-reliant and have a sense of belonging by being socially involved where they can.

A care coordination programme can be of help in all situations including stressful conflict situations in which people need care and social support because it is designed to regulate both skilled and unskilled care providers by building their capacity to provide quality care and avoid being at risk for psychological harm. Older adults who are experiencing traumatic life events including healthcare issues and have difficulty in self-management of their chronic illnesses and caring for themselves and are highly at risk for nursing home care, can be provided with quality support services in terms of long-term care to enable them live longer, better, healthier, happier lives on their own in their homes, be socially engaged, age with dignity and in place in their communities. The care coordination programmes for older adults in the United States can provide supportive home care for frail older adults in need of health and social services. A home help coordinating agency arranges for a care provider who gives special attention to the needs of older adults who experienced traumatic and stressful life events, chronic diseases, lack of social support, have low incomes, substance use disorders, Parkinson's diseases, 
diabetes, depression, dementia, rheumatism, lowered reaction time, slurred speech, Alzheimer's disorder, or other forms of emotional mental disorders. Such elders may need professional intervention to enable them prevent posttraumatic stress disorder and maladaptive or ineffective stress coping strategies such as the abuse of alcohol especially in conflict situations.

Ejikeme (2010) reported that in African traditional societies including Nigeria, the tendency to attribute some psychosocial and medical problems such as the above mentioned age-related problems to the role of evil spirits and man-made factors is common. Changing unscientific beliefs and harmful beliefs about the causation of psychosocial and medical problems among older adults, who, over years have become culturally conditioned to believe that most illnesses are caused by supernatural forces and evil machination by wicked people and often have fictions and misconceptions about illness causation, demands the expertise of professionals in the area of attitude and behaviour change. Ejikeme (2012) explained that what is culturally believed to be the cause of a disorder largely determines the type of treatment sought in the culture concerned and that this partly explains why professional counsellors, social workers, gerontologists, psychologists and other human service providers are often considered as helpers as a last resort in Nigeria.

The involvement of professional counsellors, social workers, gerontologists, and psychologists in case management or coordination of services for the prevention and management of substance and stress-related medical problems among older adults can effectively address unscientific beliefs and harmful cultural, traditional and religious beliefs about the causation of such problems. These professional helpers need to be more effective in their effort to increase the awareness of the public including older adults who are prospective end users of their services. For Americans, senior centers, mental exercise, regular physical exercise for fitness, education for wellness, assisted nutrition, assisted housing, lifelong learning, provision of health care and social security are conventional means of addressing the psychosocial and medical needs of older people. Regular physical exercise may not necessarily mean the use of gym facilities; it could be achieved by taking a walk around one's residential building for 30 minutes in the evenings five days a week from Monday to Friday. Nigerians who walk to their distant farms where they engage in strenuous farming during a larger part of the week can achieve the health benefits of physical exercise without using machines.

\section{Statement of Problem}

Assessing and providing the needed social support, counselling and psychological needs of older adults especially in conflict situations are tasks that demand the knowledge of expertise of helping professionals such as social gerontologists, clinical social workers, psychologists and counsellors. There is little or no research evidence on the psychosocial impact of these frequent and severe conflicts on older adults and the psychological and social support services for them in Nigeria. The present situation in which social workers, 
counsellors and psychologists are not involved in the provision of social support services to older adults who are victims of internal displacement due to conflicts and flood disaster leaves more to be desired and needs changing. So far, there is no literature evidence to show that something is being done to change the problem. But not doing anything in terms of research to understand the alcohol behaviour of this cohort of older Nigerian adults will be risky; drug research findings enhance evidence-based intervention that can enable drug using older adults live healthy lives.

The likely consequences of not having research based on the experiences and social support needs of this cohort of older adults in the country can be serious. They include leaving them with unmet psychosocial needs and other physical and mental health needs that can hinder their healthy living, reduce their quality of life and life expectancy. This paper, therefore, examines how the provision of social work and counselling social services as social support network can be used to help older adults cope with stress in conflict situations in Nigeria. It views social support as an approach that can enhance the stress-coping abilities of older adults in violent and non-violent situations.

\section{Significance of the Study}

The scientific understanding of the impact of religious and ethnic conflicts on older adults in Nigeria and how they cope with these conflicts will be beneficial to the older adults in camps as the primary beneficiaries, and also to social service and counselling service providers who are professionally expected to be evidence-based in addressing the psychosocial needs of victims of conflicts of all ages in the country. The outcome of this investigation is expected to be beneficial to the cohort of internally displaced persons that are older adults who lack social support in conflict situations in the country. It is also expected that if this investigation of the social support needs of older Nigerian adults in conflict situations is adequately handled, its outcome will reduce the burden being faced by the corroding extended family members that used to be effective in providing social support to older adults but in recent times, are increasingly at risk for anxiety, stress, and burnout disorders in the country due to increasing rates of conflicts, poverty, unemployment, inflation and social deprivation. Finally, the data to be obtained on the cohort of older Nigerian adults who are victims of conflict situations in Nigeria will guide the formulation of social policy in the country and spur further studies in the field.

\section{Methodology}

The authors utilized data on a cohort of older adults from the work of Akwash (2008) on Psychological consequences of internal displacement on victims of communal conflicts in Nasarawa State, North Central Nigeria. The support provided in camps where they are resettled is compared with the situation in 
other countries, such as the USA, with appropriate social support including counselling and psychological needs of their older populations in war and conflict situations.

This study used a desk-based, exploratory literature search as its design involving the use of secondary data from Akwash's (2008) work. Based on nature of the study population, Akwash used the following instruments: General Health Questionnaire (GHQ) by Guldberg (1970), Eyesenck Personality Questionnaire (EPQ) by Eyesenck (1978), Becks Anxiety Inventory (BAI) by Becks and Forgiveness versus Reconciliation Attitude Scale (2006) by Nweze. The Life Changes Questionnaire by Miller and Tahe (1997) was used to probe life change events in relating to the health, work, personal, social home, family and financial aspects of the lives of the internally displaced persons.

The purpose of reviewing Akwash's (2008) empirical research culled from his doctoral thesis is to:

(a) find out from literature how counselling and psychological needs of elders in war and conflict situations are met in the USA;

(b) identify the psychosocial needs and problems of older persons internally displaced and dislocated by religious and ethnic crises in the country that could lead them to use alcohol or increase its consumption for coping with stress;

(c) examine the appropriateness and effectiveness of the coping responses used by distressed older adults as victims of religious and ethnic crises;

(d) explore the extent of the involvement of medical social workers, clinical psychologists and counsellors in understanding the concerns of victims of crises and helping them to derive maximum benefits from medical care in the country - through timely and appropriate referrals, needs assessment, treatment, preventive interventions, relapse prevention and rehabilitation services.

\section{Findings}

Data for this paper were obtained from the major findings of a $\mathrm{PhD}$ researchbased report by Akwash (2008). This served as a case illustration of how social and psychological factors can lead to anxiety, stress and psycho-physiological disorders and general medical or psycho-physiological conditions of internally displaced older persons due to recurring inter-ethnic and inter-religious crises in Nigeria. In line with the major objective of the present exploratory study, Akwash (2008) attempted to understand the potential of a sample of internally displaced persons, victims of inter-ethnic and inter-religious crises for medical problems and their underlying psychosocial factors. A total of 373 internally displaced person including older adults participated in Akwash's study carried out in North-Central zone of Nigeria. The relevant findings from the study are presented in Table 1 below. 
Table 1: Coefficient indicating EPQ categories predictor: Evidence of psychosocial needs and problems among internally displaced persons

\begin{tabular}{|c|c|c|c|c|c|}
\hline Model & \multicolumn{2}{|c|}{$\begin{array}{c}\text { Unstandardized Standard } \\
\text { Coefficients }\end{array}$} & $\begin{array}{c}\text { T } \\
\text { Coefficients }\end{array}$ & Sig. & \\
\hline Constants & B & Std Error & Beta & 9.709 & .000 \\
\hline EPQ & 32.744 & 3.372 & -2.140 & .033 & \\
\hline EXTROVERSION & .549 & .257 & -118 & 1.653 & .099 \\
\hline EPQ & & & & & \\
\hline NEUROTICISM & .401 & .242 & .091 & -489 & .625 \\
\hline EPQ & & & & & \\
\hline LIE & .112 & .229 & 0.25 & -1.180 & .239 \\
\hline EPQ & & & & & \\
\hline PSYCHOTICISM & .291 & .246 & .061 & & \\
\hline
\end{tabular}

Source: Akwash, F.B.A., 2008

With respect to the coded words in Table 1, (a) EPQ refers to Eysenck Personality Questionnaire, (b) EPQ ETROVERSION measures if the elderly victim of violence and displacement is outgoing, talkative or energetic in behaviour, (c) EPQ NEUROTICISM measures the state of the victim in terms of positive or negative emotional status, good or bad mood that can either curb or escalate violence, (d) EPQ LIE measures whether or not the victim of violence and displacement is lying in reporting his condition as a displaced person such as when a drug abusing elderly victim of displacement denies being upset about loss of home care, denies anger towards perpetrators of ethno-religious violence, denies emotional disturbance leading to increased drug use, and (e) EPQ PSYCHOTICISM measures whether or not the victim expresses some aggression, violence, learned helplessness, aloofness and impulsive actions. The above measures guide counsellors, social gerontologists, psychologists, and social workers figure out the psychosocial needs and problems of a victim of violence and displacement such as how he or she thinks about a traumatic life event like violence induced-displacement as a determinant of the level of stress experienced.

Table 1 shows that some of the older adult victims of internal displacement in Akwash's study manifested the signs and symptoms of psychosocial needs and problems such as troublesome anxiety, stress, extroversion, depression, neuroticism, lie and were tempted to increase their use of alcohol to cope with stress of ageing and displacement. Akwash also reported that many of the older adult participants relative to the younger-aged cohort in his study of internally displaced persons in Nigeria showed unwillingness to forgive the perpetrators of the inter-religious and inter-ethnic conflicts and hostilities that resulted in their internal displacement in a Nigerian environment. A highly significant finding of the review of Akwash's research work is that despite the presence of 
these stressors that tempted the internally displaced older adults older adults, they were only visited by nurses and medical doctors but not by social workers, counsellors, psychologists and other human service providers who could adequately, effectively and appropriately provide social support, and psychotherapeutic services to meet their unique concerns and prevent them from using alcohol as a coping strategy. The prevention of drug abuse among older adults is basic, essential step towards the prevention of HIV infection, dementia, and suicide risk among them (Ejikeme \& Ejikeme, 2012). And so, the finding that the substance related disorders of the internally displaced adults in Nigeria were neither diagnosed nor treated by gerontological/clinical social workers, clinical psychologists, and counsellors shows the neglect of at risk elders in the country.

Evidence from the Table 1 shows that there are psychosocial needs and problems of older persons internally displaced and dislocated by religious and ethnic crises in Nigeria that could lead them to use alcohol or increase its consumption for coping with stress especially as their residential environment was not smoke free and alcohol use was not controlled. The coping responses to traumatic stressful experiences used by the older adults as victims of religious and ethnic crises such as increased drinking were inappropriate and ineffective and if not treated by psychologists could lead to posttraumatic stress disorder among them. Only medical doctors and nurses were involved in addressing the needs of all the internally displaced persons in camps studied by Akwash (2008) and so there was no involvement of volunteers, medical social workers and clinical psychologists in understanding the concerns of victims of crises and helping them to derive maximum benefits from medical care in the country - through timely and appropriate referrals, need assessment, treatment, preventive interventions, relapse prevention and rehabilitation services.

The findings of this needs assessment had highlighted the unidentified, undiagnosed and untreated co-occurring drug disorders of internally displaced older adults in conflict situations in Nigeria and will be beneficial to their communities if they are made to become aware that drug abuse can co-occur with HIV infection and mental illness; such awareness will stimulate their family, other care givers and communities to help them treat and prevent their drug problems.

\section{Contribution to the Understanding of the Situation of the Elderly in Nigeria}

Findings in this study provide the basis for brief but useful comparative analysis of the situation the elderly and the quality of care for them in Nigeria and America. For instance, while in the US elders especially those in need of social support and care tend to move into senior centres and assisted living facilities, the elderly victims of internal displacement due to violence and natural disasters in Nigeria preferred be in their homes for care for the rest of their lives; being conditioned to extended family support system which is typical of their home communities. And so, they considered rehabilitation 
camps where they were placed as internally displaced persons as liabilities and care facilities of the last resort. As stated earlier, of all the numerous senior centres or facilities for the care of older adults in America, in-home and community-based care services have prospects of meeting the health, learning, nutritional, fitness, housing, safety and security needs of older adults with health and social challenges in Nigeria. The use of the volunteer system in the provision of in-home and community-based care services and support for seniors in need is common and cost effective in the US. The use of volunteers in providing care for frail elders with chronic disabilities in Nigeria is as rare as such care facilities are in the country. The rehabilitation camps where these older adults and other victims of violence and displacement were placed for care in Nigeria were neither smoke free nor controlled by restrictions on the use of alcohol and other substances that can exacerbate ageing problems. Many senior centres in America are smoke free and have drug counselling services.

\section{Recommendations}

The violence in North-Eastern Nigeria, which appears to be on the rise despite existing efforts to prevent and manage it, has been found in this study to be exacerbating the ageing problems and situation of its elderly victims. Considering that violence leading to the internal displacement of persons reflects the loss of control of negative emotions by its perpetrators and that its elderly victims have not been effective in coping with their stressful violent situation, the issues involved emanate from body and mind. And so, efforts to curb violence and improve the situation of its elderly victims in Nigeria need to include social support as an approach that can enhance the stress-coping abilities of older adults in violent and non-violent situations.

This paper therefore recommends that the services of counsellors, social gerontologists, social workers, and psychologists should be considered to imperative in efforts designed to enable elderly victims of violence and displacement in Nigeria to cope successfully with stressful challenges without resorting to the abuse of drugs which can exacerbate their age-related problems. Also noting from literature review and the result of this study that increased alcohol use leads to violence and that the stress-coping strategies of the elderly victims of conflict and displacement involved in increased alcohol use, it is recommended that drug education by counsellors, psychologists and social workers should intensified to cover both the younger and older generations in Nigeria.

Considering the importance attached to the extended family support in Nigeria, in-home care should be adequately provided for elderly persons especially in rural areas in the country. Noting that there is the scarcity of human service providers that can respond effectively to the psychosocial needs of older adults in conflict situations in the country, it is recommended that 
there should be specific policy, health care and social support responses to the needs of the elderly in both rural and urban populations in Nigeria. The twentyfour Nigerian University Scholars sponsored by the National Universities Commission, Abuja, Nigeria to undertake a specialist course in Ageing at the University of North Texas, USA, include professional counsellors, social gerontologists, sociologists, psychologists, social workers and other human service providers that can assist traumatised elders cope effectively with the stress of conflict situations in the country. It is therefore recommended that they should be encouraged to participate in efforts to improve the situation of the elderly in Nigeria once they complete their Applied Gerontology programme.

\section{Conclusion}

This research work has used supportive literature to assess the nature and scope of psychological treatment and interventions for internally displaced older adults who increased the use of alcohol and other drugs as coping strategies and found that the psychosocial needs of these older adults have been neglected. This assessment is primarily beneficial to the cohort of Nigerian elders with undiagnosed and untreated drug problems. It is also beneficial to their families who will be relieved from the stress and burden of caregiving.

The findings of this needs assessment which have highlighted the unidentified, undiagnosed and untreated co-occurring drug disorders of older adults in Nigeria will be beneficial to their communities if they are made to become aware that drug abuse can co-occur with HIV infection and mental illness; such awareness will stimulate their family, caregivers and communities to help them treat and prevent their drug problems. It is also relevant to social policy formulation in Nigeria for this research project anchored on the assessment of the needs of displaced older adults at risk for co-occurring substance related disorders; draws attention to the need to prevent adult drug abuse as an effective means of preventing the spread of HIV infection among them and in their immediate community in Nigeria. Thus, this research project evaluation has helped to prepare the service professionals to conceptualize and respond to community readiness to service the changing needs of an ageing society in such areas as access to mental health service and provision of lifelong education for internally displaced older adults compelled by life events to increase alcohol and other drug consumption as means of coping with stress in Nigeria. These are the means of evaluating the outcome of this research project in Nigeria and so, the findings have justified the purpose of the study.

The following conclusions arise from the review of findings obtained from Akwash's research work on Psychological Consequences of Internal Displacement on Victims of Communal Conflicts in Nasarawa State, North Central Nigeria. The older adults who were traumatized as a result of internal displacement were not willing to forgive those they perceived as the perpetrators of their traumatic experiences. Also the service delivery systems and their providers in the camps for internally displaced persons were not well- 
equipped to meet the psychosocial needs of older adults with alcohol use problems. Many of the elderly victims of violence and displacement interviewed reported that they preferred in-home care to placement in camps away from their home communities.

\section{References}

Asiyanbola, R. Abidemi. 2006. Assessment of Family Care, Housing, Gender, Daily Activities, and Physical Wellbeing of the Elderly in Ibadan. Nigeria ASSET Series C (2008). 3(1): 63-78.

Ajomale, O. 2007. Country report: ageing in Nigeria: Current state, social and economic implications. Summer Newsletter of the Research Committee (RC11) on sociology of ageing of the International Sociological Association (ISA), Oxford Institute of Ageing. 115-20.

Akwash, F.B.A. 2008. Psychological consequences of internal displacement on victims of communal conflicts in Nasarawa State, North Central Nigeria. A $\mathrm{PhD}$ thesis submitted to the Department of General and Applied Psychology, University of Jos, Nigeria.

Araba, N. 2013. Rapid urbanization and living arrangements of older persons in Africa. Retrieved from www.un.org/esa/population/.../apt.pdf

Berman, B. 2006. Handbook of social work in health and ageing. New York: Oxford University Press.

Corley, C.; Gray, M. \&Yakimo, R. 2006. Substance abuse networks. In B. Berkman (ed.). Handbook of social work in health and ageing. New York: Oxford Press.

Ejikeme, G.G. 2010a. Low emotional intelligence, drug abuse, and child maltreatment. Implications for psychological and social work services. Professorial Inaugural Lecture. The University of Jos Inaugural Lecture Series 40, March 5, 2010. Jos: Information and Publications Division, University of Jos \& University of Jos Press Ltd.

Ejikeme, G.G. 2012b. The roles of Nigerian scholars and professionals in diaspora in Nigeria's educational development: A case for transformational leadership. ASUU Journal of Social Sciences: A Journal of Research and Development. 1(1): 105-145.

Ejikeme, G.G. 2014c. Helping older adults live longer, healthier, better, and happier lives on their own. University of Jos Memos, A monthly Bulletin, 17(6): 17-19.

Ejikeme, G.G. \& Ejikeme, T.U. 2013.Counselling and social work services for older adults with substance use disorders in Nigeria. Paper presented at the National Conference of the Nigerian Association of Social Work Educators (NASWE) held at the University of Benin, Nigeria, 13-16 March, 2013.

Fellin, P.A. \& Powell, T.J. 1988. Mental Health Services and older adult minorities. The Gerontologist. 28(4): 442-447. 
Giddens, A. 2010. Sociology. Malden, USA: Polity Press.

Glatt, M.M.; Rosin, A.J. \& Jauhar, P. 1978. Alcoholic problems in the elderly. Age and Age and Ageing. 7: 64-71.

Hunsberger, B. 1985. Religion, age, life satisfaction, and perceived sources of religiousness: A study of older persons. Journal of Gerontology. 40: 615620.

LaGreca, A.J.; Akers, R.L. \& Dwyer, J.W. 1988. Life events and alcohol behaviour among older adults. The Gerontologist. 28(4) 435-572.

Rostow, W.W. 1961. The stages of economic growth. Cambridge: Cambridge University Press.

Shibusawa, T. 2006. Older adults with substance/alcohol problems. In B. Berkman (ed.). Handbook of social work in health and ageing. New York: Oxford Press.

Stockwell, T.; Hodgson, R. \& Rankin, H. 1982. Tension reduction and effects of prolonged alcohol consumption. British Journal of Addiction. 77: 66-73.

Tylor, R.J. \& Cahtters, L.M. 1988. Correlates of education, income, and poverty among aged blacks. The Gerontolgist. 28(4): 435-442.

Wilson, G. 2007. Globalisation and support in old age. Retrieved from http://eprints.lse.ac.uk/arcive/00001032.

University of Liverpool. 2013. Traumatic life events biggest cause of anxiety and depression. Retrieved from http:www.science daily.com/releases/2013/10/1310i6213223.htm.

Williams, S.J. \& Torrens, P.R. 2008. Introduction to health services. New York: Demar Cengage Learning. 